\title{
Work-related stress among the university librarians of Sri Lanka
}

Wijetunge, Pradeepa ${ }^{1}$

\begin{abstract}
Sri Lankan university sector is changing rapidly as a result of educational reforms and the government's emphasis on a knowledge economy. As a consequence, the work environments of the university librarians are also changing. Although this environment can serve as a factor for increased work-related stress of the Librarians there is no evidence of any empirical studies related to stress of Sri Lankan University Librarians. This study was carried out with the objective of understanding the trend of stress among the University Librarians and to fill a void in the literature. This study was limited only to the University Librarians who are the Heads of the Libraries but not the other librarians below the rank of University Librarians. To suit the Sri Lankan needs a 95 item instrument which measured the stress level under employment, professional, administrative and health was designed based upon CAUT Survey (Catano 2011). Total Stress levels vary from Librarian to Librarian but five could be grouped into Medium Stress category with two in the High Stress category. Of the four domain surveyed, Physical Domain proved to be the least stressful domain while the Administrative Domain proved to be the highest stressful. Based on the previous studies researchers have discovered that performance improved with increased stress to an optimal point. Studies have proved resilient people found a stressful event intriguing and challenging. Considering these findings it was recommended that no initiative should be taken to reduce the current stress levels of the Sri Lankan University Librarians so that their stress factors are considered as a challenge and transformed into positive outcomes.
\end{abstract}

\section{Introduction}

Stress can be categorized as physical or psychological. "Physical stress is one that irritates or brings immediate or long term negative effects on one's physical health but not necessarily on one's mental status. Psychological stress is what brings immediate or long term irritation or negative effects on one's mental status which may not necessarily have

\footnotetext{
${ }^{1}$ Librarian, University of Peradeniya, Sri Lanka. Email: librarianpdn@gmail.com
} 
Journal of the University Librarians Association, Sri Lanka, Vol. 16, Issue 2, July 2012

any immediate effect on one's physical status but these two can be interactive" (Ajala 2011). Stress also has been categorized as "acute (immediate) and chronic (long-term) (Lehnert 2002). Acute stress can be one-time incident that comes and goes quickly and its effects can last for minutes, hours, days or weeks while chronic stress can be caused by a continuing string of stressful incidence of an ongoing situation". Discussing stress in academic context Duze (2011) comments that, "stress is the psychological and emotional reaction to psychological events. It can be described as an individual's continous feeling of worry about life which prevents the individual from relaxing and enjoying a high level of well-being." Duze (2011) further comments that job stress in tertiary institutions is something that all academic and administrative staff encounter.

\section{Review of Literature}

Although there are numerous studies on stress of other professionals, studies on stress related to librarians was limited to general discussions and observations until early $1980 \mathrm{~s}$ and despite a few research studies, librarians have little statistically valid or scientific research about the impact of stress son librarians (Wood 1989). Roose (1989) has found that 42 per cent of the reference librarians experienced high stress and job burnout due to their adverse work environment. Neville (1981) has established that academic reference librarians and service staff were stressed because they were increasingly expected to provide information services. Wood (1989), using Hallberg's Stress Survey established that there is no evidence of unhealthy stress levels among the academic librarians. Nevertheless this trend seems to have changed in the later years. As Ajala established in 2011 the fast paced library environment is calling for more than what the professionals did in the past and this is coupled with the development of information technology now being introduced to the profession. All these factors have turned the library profession into a stressful and high risk profession. Ajala (2011) quotes several studies (Hack, Jones and Roose (1984), Nawe (1995), Routray and Satpathy (2007) and Schneider (1991)) which proves that the library profession is becoming stressful due to technology, role conflict and many other causes. 
Journal of the University Librarians Association, Sri Lanka, Vol. 16, Issue 2, July 2012

Sri Lankan university sector is changing rapidly as a result of educational reforms and the government's emphasis on a knowledge economy. As a consequence, the work environments of the university librarians are also changing. Funding is increasingly reduced for books and periodical acquisitions while the student intakes are annually increased. Instead of the year-end examinations now the universities have introduced the semester system which continuously increases the demand on library material and services. There is a need to introduce new information technologies and to re-orient the services and organisational structures to accommodate changes brought in by the technology. Staff numbers are reducing due to government policies and the librarians are constantly challenged to provide a better service for more and more users with dwindling resources. Although this environment can serve as a factor for increased work-related stress there is no evidence of any empirical studies related to stress of Sri Lankan University Librarians. Hence this survey was carried out with the objective of gaining insights into the trend of stress among the University Librarians and to fill a void in the literature related to the stress of Sri Lankan university librarians.

\section{Limitations of the Study}

Firstly, this study covered only the University Librarians who are the Heads of the Libraries but not the other librarians below the rank of University Librarians. Stress levels may be different among Assistant Librarians, Senior Assistant Librarians and Deputy Librarians. Therefore the outcomes may not be generalized for the entire university librarianship. Secondly, there was no evidence of previous stress measurements in the context of Sri Lankan university librarianship, therefore any literature or empirical data to base the current study on was absent. Thirdly, due to time limitation and small sample size it was not possible to pilot the survey instrument. Fourthly, the response rate was 46 per cent. However there is no significant impact on the findings as the sample is a rather homogenous group. 
Journal of the University Librarians Association, Sri Lanka, Vol. 16, Issue 2, July 2012

\section{Methodology}

The survey instrument was developed using the Librarians' Stress Survey Instrument of the Canadian Association of University Teachers (Catano 2011). This original instrument is a 19 page document covering six domains; job, work environment, work activities, job satisfaction, health and personal information. The instrument has used 207 Likert type statements to measure the stress levels and has warned that it can take 30-40 minutes to be completed. Even if this CAUT survey instrument is very comprehensive a special instrument had to be developed for the Sri Lankan study for several reasons; 1)The Sri Lankan survey was intended only to measure the stress levels of University Librarians (the term "Librarian" is used here to denote the Head of the university library but not as a generic term which covers various grades of librarians such as Assistant Librarian, Senior Assistant Librarian and Deputy Librarians) and many statements in the CAUT survey were irrelevant to the cultural and employment context of the Sri Lankan University Librarians. 2) Although highly comprehensive, the time required to complete the questionnaire was too long for the Sri Lankan survey. Data collection had to be completed within five working days and requesting the Librarians to allocate 30-40 minutes or more for a questionnaire would not have yielded a reasonable response rate and 3) The Sri Lankan survey only paid attention to the administrative and management role of the Librarians, therefore these areas had to be designed to suit the Sri Lankan context.

To suit the need of the study a four page, 95 statement instrument which measured the stress level under four domains (employment, professional, administrative and health) with 15 sub domains was prepared. Personal information of those responded were also added later. While most statements from the job and the health sections of the CAUT survey were used many new statements relevant to the Sri Lankan context were added. Respondents were asked to mark their agreement or disagreement in a continuum of five options varying from Strongly Agree to Strongly Disagree and a sixth "Don't Know" option was also provided. 
Journal of the University Librarians Association, Sri Lanka, Vol. 16, Issue 2, July 2012

\section{Sample}

Thirteen universities under the jurisdiction of the Sri Lankan UGC were considered for the survey leaving out two universities (one where the researcher is employed and another university where a Librarian or an Acting Librarian is still not appointed) The survey instrument was e-mailed to 13 Librarians with a request to return it within five working days. Eight were returned which is $61 \%$ of the total sample. The non response could be attributed to absence of connectivity due to technical problems, absence from office and not having enough time to respond.

The personal characteristics of the respondents indicate that it was a homogenous group. Six of them were in the age group 51-60 while two were in the age group of 41-50. There were six females and two males and all have completed Masters in Librarianship. One has completed doctoral degree while three are engaged in research towards doctoral degrees. All except two Librarians had experience in the library profession for 20 or more years while two Librarians had 15 years of experience but the experience as the Librarian could be categorised in to three groups; 1-5 years, 6-10 years and 11-15 years and Table 2 illustrates the details.

\section{Data Interpretation}

For the ease of interpretation, responses were assigned numeric value in such a way that a higher numeric value was assigned to factors that can cause high stress and a lower numeric value was assigned to factors that can cause low stress. The highest numeric value assigned for a single option was 5 while the lowest was 1 and "Don't Know" category was assigned 0 . The highest overall score that could have been assigned by a respondent to the whole instrument was 475 while the lowest overall score that could have been assigned was 95 . This overall maximum score was divided into five categories of stress levels as given below so that according to the total score of the individual Librarians, the stress level of each could be defined. 
Journal of the University Librarians Association, Sri Lanka, Vol. 16, Issue 2, July 2012

Table 1: Definition of stress level according to numeric value

\begin{tabular}{l|c}
\hline Range of scores & Definition assigned \\
\hline $00-95$ & NoStress \\
$96-190$ & LowStress \\
$191-285$ & MediumStress \\
$286-380$ & High Stress \\
$381-475$ & VeryHighStress \\
\hline
\end{tabular}

\section{Findings}

Following sections present the findings related to overall stress, the relationship between stress and experience as a Librarian, domain-specific stress levels and stress related to Administrative Domain. Administrative domain is specifically discussed here as it the Librarians show highest stress levels in this domain.

\section{Overall stress level}

Figure 1 depicts the total individual scores of each Librarian and it indicates that the stress levels vary from Librarian to Librarian but they all can be grouped into Medium Stress category (191-285) except two Librarians that falls into High Stress category (286380). Minor variations in the individual stress levels can be attributed to the variations in the individual workload, work environment, organization culture, personalities, beliefs and attitudes. This trend conforms with the findings of Wood (199) which established that there is no evidence of unhealthy stress levels among academic librarians. 


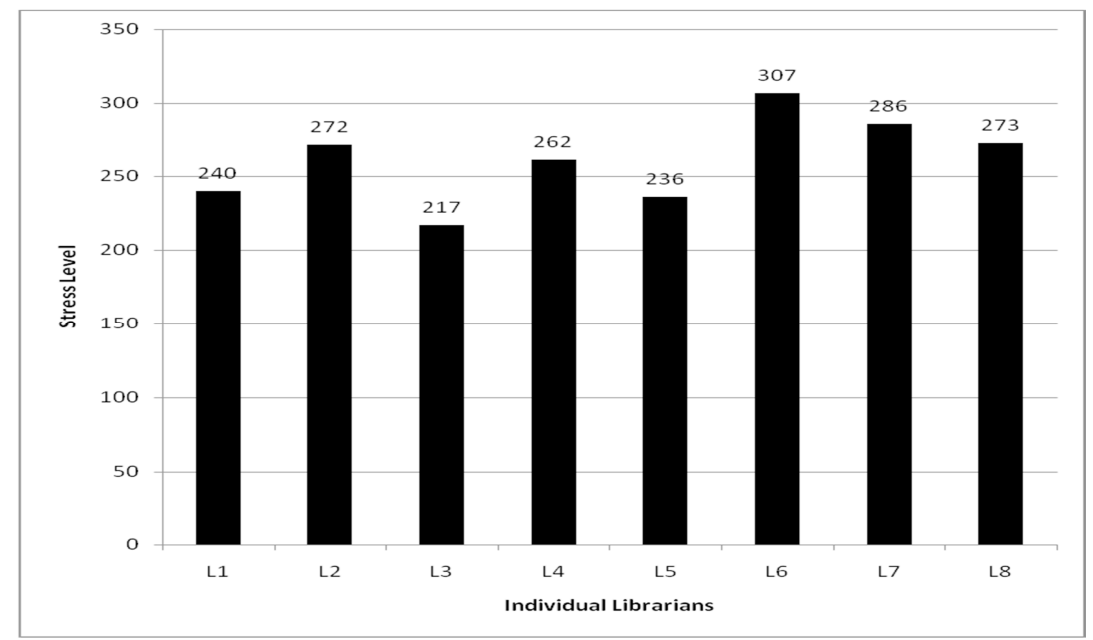

Figure 1: Overall stress levels of individual Librarians

\section{Stress and Experience as a Librarian}

The overall stress scores were compared with the level of experience as a Librarian and the data are provided in Table 2 and graphically illustrated in Figure 2. Analysis indicates that the lowest overall stress is related to one of the two most experienced Librarians but a significant relationship between the experience and stress is not evident. Rather, the stress levels seem to vary individually. Further research is required to establish the specific reasons for these variations and the time limitation available for the research did not warrant such a detailed analysis of individual cases.

Table 2: Relationship between experience and stress level

\begin{tabular}{c|cc}
\hline Respondent & No. ofyears sened as a Librarian & Overall Stress Level \\
\hline L5 & $0-5$ & 236 \\
L1 & $0-5$ & 240 \\
L2 & $0-5$ & 272 \\
L6 & $0-5$ & 307 \\
L4 & $6-10$ & 262 \\
L7 & $6-10$ & 286 \\
L3 & $11-15$ & 217 \\
L8 & $11-15$ & 273 \\
\hline
\end{tabular}


Journal of the University Librarians Association, Sri Lanka, Vol. 16, Issue 2, July 2012

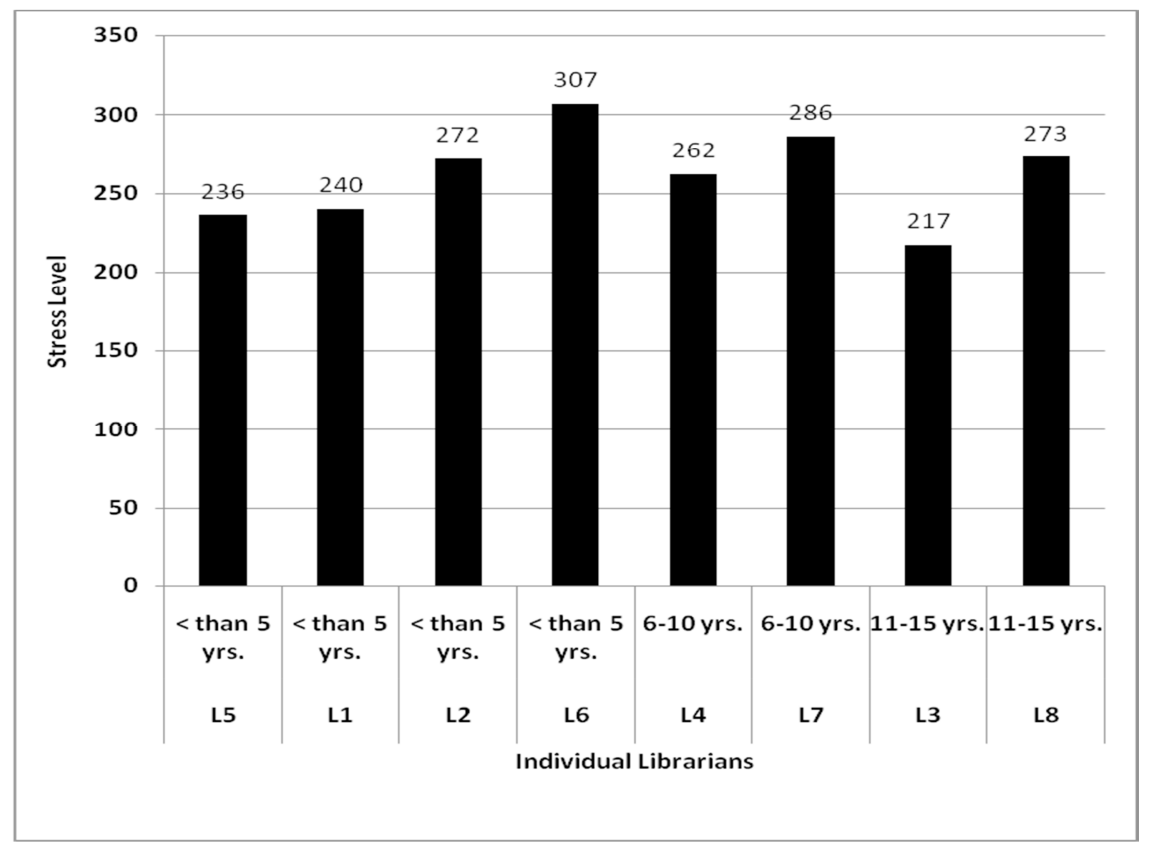

Figure 2 - Relationship between experience and stress level

\section{Domain-specific Stress}

While Table 3 provides the scores assigned by Librarians to different stress domains measured by the survey, Figure 3 diagrammatizes the domain specific stress patterns of the Librarians.

Table 3: Domain-specific stress patterns of individual Librarians

\begin{tabular}{l|llllllll}
\hline Domain & $\boldsymbol{L}$ & $\mathbf{L}$ & $\mathbf{L 3}$ & $\mathbf{L 4}$ & $\boldsymbol{L 5}$ & $\mathbf{L 6}$ & $\mathbf{L 7}$ & $\mathbf{L 8}$ \\
\hline 1.Employment Domain & 51 & 56 & 34 & 59 & 52 & 56 & 68 & $\mathbf{7 5}$ \\
2.Professional Domain & 37 & 51 & 60 & 60 & 62 & 60 & 67 & 53 \\
3.Administrative Domain & 116 & 132 & 106 & 128 & 94 & 143 & 121 & 104 \\
4.Physical Domain & 36 & 33 & 17 & 15 & $\mathbf{2 8}$ & $\mathbf{4 8}$ & 30 & 41 \\
\hline Total & $\mathbf{2 4 0}$ & $\mathbf{2 7 2}$ & $\mathbf{2 1 7}$ & $\mathbf{2 6 2}$ & $\mathbf{2 3 6}$ & $\mathbf{3 0 7}$ & $\mathbf{2 8 6}$ & $\mathbf{2 7 3}$ \\
\hline
\end{tabular}




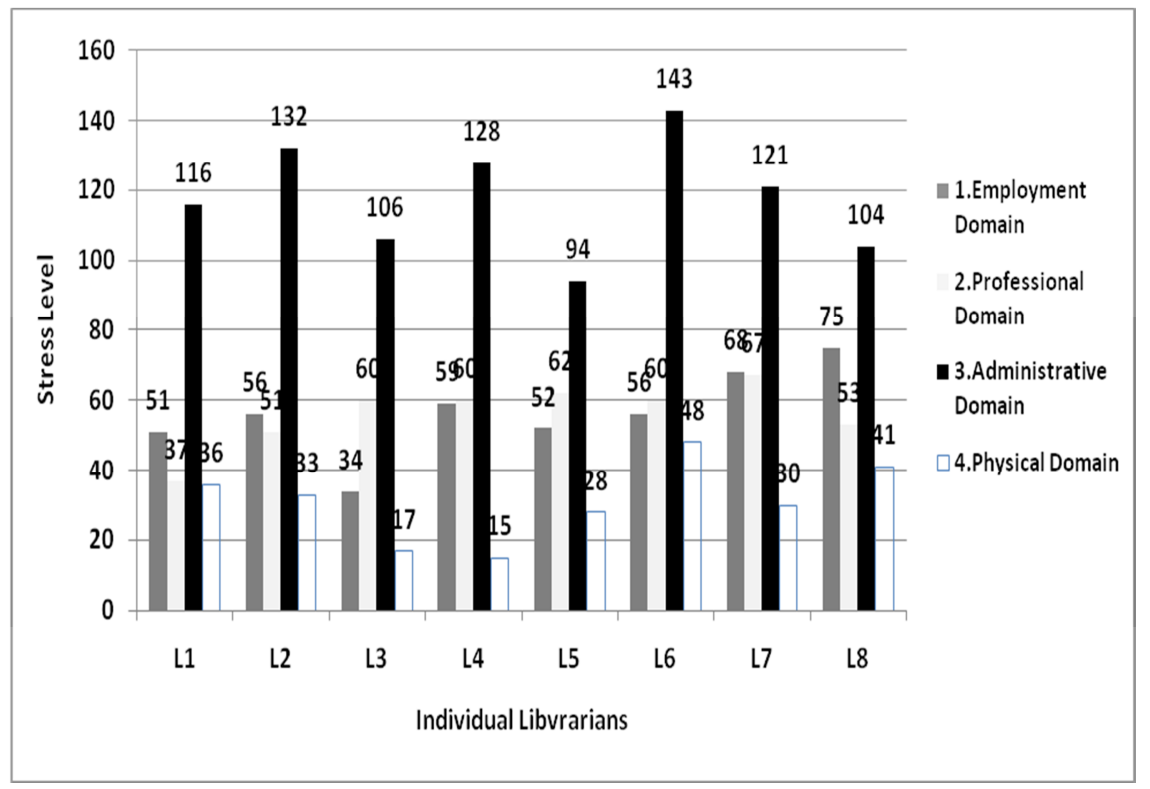

Figure 3: Domain-specific stress patterns of individual Librarians

Physical Domain which measured 13 different stress related illnesses is the least stressful domain for all Librarians according to Figure 3. Employment Domain which indicates the second lowest stress levels was measured using employment related control, workload, work scheduling, role conflict, role ambiguity and routinisation by means of 25 statements. Two Librarians have indicated lower stress levels (17 and 15) in this domain than the others. The third lowest level of stress is indicated in the Professional Domain. Stress level of this domain was measured using of skills, recognition of the profession within the institution/ society and relationships with other Librarians by means of 22 statements. The Administrative Domain seems to be the highest stressful domain of the Librarians. Stress level of this domain was measured using four sub domains and due to its significance in the survey of stress levels of the Librarians it is further analysed in a following section.

Analysis of the individual scores of different domains indicate several minor deviations from the normal patter, for instance stress level of L3 in employment domain is lesser than that of the others, L1 and L2 have slightly lower stress in the professional domain 
Journal of the University Librarians Association, Sri Lanka, Vol. 16, Issue 2, July 2012

that the others, L5 shows a lower level of stress that the others in administrative domain and L3 and L4 have lower stress levels than the others in health domain. These individual variations can be attributed to the variations in individual workloads, work environments and organisational cultures.

\section{Administrative Domain}

Table 4: Scores of administrative stress of librarians

\begin{tabular}{l|llllllll}
\hline Administrative Domain & $\boldsymbol{L}$ & $\mathbf{L}$ & $\mathbf{L 3}$ & $\mathbf{L 4}$ & $\mathbf{L 5}$ & $\mathbf{L 6}$ & $\mathbf{L 7}$ & $\boldsymbol{L 8}$ \\
\hline Finance & 17 & 21 & 18 & 24 & 16 & 23 & 23 & 11 \\
HR(Academic) & 38 & 37 & 29 & 41 & 34 & 37 & 40 & 36 \\
HR(Non Academic) & 33 & 47 & 33 & 38 & 34 & 46 & 30 & 34 \\
Working relationship with administration & 28 & 27 & 26 & 25 & 30 & 37 & 28 & 23 \\
\hline Total Score & $\mathbf{1 1 6}$ & $\mathbf{1 3 2}$ & $\mathbf{1 0 6}$ & $\mathbf{1 2 8}$ & $\mathbf{9 4}$ & $\mathbf{1 4 3}$ & $\mathbf{1 2 1}$ & $\mathbf{1 0 4}$ \\
\hline
\end{tabular}

Stress levels in the Administrative Domain were measured using four sub domains; Finance, Human Resources (Academic), Human Resources (Non-Academic) and working relationship with administration (Table 4 and Figure 4). Across these four sub domains also a variation is visible with the lowest stress level with regard to the attitudes towards lack of finance. Respondents were presented with five statements which covered lack of finance for purchasing books and periodicals, library furniture, computers and other equipment and infrastructure facilities. The peak of stress levels vary among two groups of Librarians. The first group consisting of $L 1, L 3, L 4, L 5,7$ and $L 8$ indicates highest level of stress related to Human Resources (Academic) while the second group consisting of L2 and L6 indicates highest stress levels related to Human Resources (NonAcademic).Thirteen statements which covered unfilled cadre vacancies, staff : user ratio, training opportunities, staff relationships, their attitudes towards change, their innovativeness and recruitment policies and procedures measured their stress levels with regard to these two staff categories and the reasons for higher stress levels could be attributed to various institutional specific factors. 


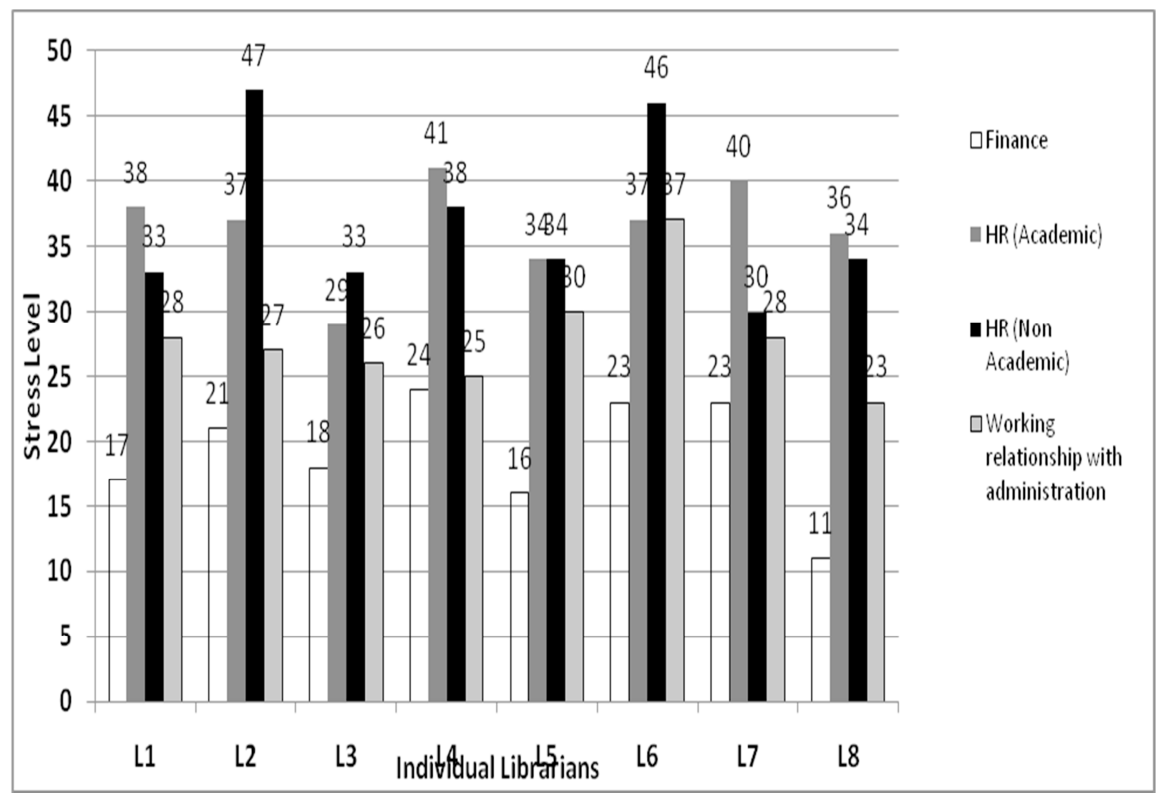

Figure 4: Stress levels of individual Librarians in the Administrative Domain

\section{Conclusions and Recommendations}

The study conducted using a 95 item questionnaire measured the work-related stress levels of Sri Lankan university librarians in four domains; employment professional, administrative and health. The six respondents demonstrated slightly varying levels of stress but all within the Medium Stress level except one Librarian which falls in to the category of High Stress. Of the four domains, the administrative domain was the most stressful for the Librarians and out of four sub domains measured under the Administrative Domain, Human Resources sub domains, both academic and nonacademic were the most stressful for the Librarians.

The study did not establish that the Sri Lankan University Librarians need any extra measures to reduce the stress levels. Based on the previous studies researchers have discovered that performance improved with increased stress to an optimal point (Yerkes and Dodson 1908). Spielberger (1966) has focused on the positive effects of anxiety and stress on the individual's drive system which provided motivating information or signals 
Journal of the University Librarians Association, Sri Lanka, Vol. 16, Issue 2, July 2012

when it was operating. As Wood (1989) quotes that "Maddi and Kobasa's research (1984) has proved that executives who scored in the high stress range on life event checklists but scored low on illness checklists had a high personality hardiness score. Their low stress was attributed to a healthy family atmosphere involving a varied environment including the performing of many medium difficulty tasks, expression of the importance of individuality and diversity. Their study also showed that Hardy people found a stressful event intriguing and challenging. They felt confident and positive that they influenced the outcome of a highly stressful even. This was transformed into some less stressful form to protect their health." (Wood 1989: 7-8). In 2009, Hansen asserted that infrequent doses of job stress pose little threat and may be effective in increasing motivation and productivity, but much or prolonged stress may lead to both professional and personal downward spin which can lead poor health and injury. Considering these findings it is recommended that no initiative should be taken to reduce the current stress levels of the Sri Lankan University Librarians so that their stress factors are considered as a challenge and transformed into positive outcomes. Nevertheless, further detailed research is necessary to establish the findings of this survey.

\section{References}

Ajala, Emmanuel Babatunde (2011). Wor-related stress among Library and Information professionals in a Nigerian University. Library Philosophy and Practice. Retrieved from: http://unllib.unl.edu/LPP/ajala.htm Accessed on 28.12.2011

Catano, Victor M. et.al (2011). CAUT Librarians Stress Survey. Retrieved from: http://infopoll.net/live/surveys/s35601.htm Accessed on 26.12.2011

Duze, Ogoamaka, Chinelo (2011). Job stress, workload, academic freedom and quality research in Nigerian universities. Academic Leadership: The online Journal. 9 (2). Retrieved from: http://www.academicleadership.org/1447/job-stress-workloadacademic-freedom-and-quality-research-in-nigerian-universities/

Hansen, S.R. (2009). Ten tips for finding life balance in college. Key study tools to achieve academic success. http://www.mycollegesuccessstory.com Quoted in Duze, Ogoamaka, Chinelo (2011). Job stress, workload, academic freedom and quality research in Nigerian universities. Academic Leadership: The online Journal. 9 (2). http://www.academicleadership.org/1447/job-stress-workload-academic- 
Journal of the University Librarians Association, Sri Lanka, Vol. 16, Issue 2, July 2012

freedom-and-quality-research-in-nigerian-universities/ Accessed on 26.12.2011

Lehnert, Paul (2002). "Stress Management" Baylor Health Care Systems. www.baylorhealth.edu quoted in Ajala, Emmanuel Babatunde (2011). Workrelated stress among Library and Information professionals in a Nigerian University. Library Philosophy and Practice. Retrieved from: http://unllib.unl.edu/LPP/ajala.htm Accessed on 28.12.2011

Hack, Mary., Jones, John. W. and Roose, Tina. (1984). Occupational burnout among librarians. Drexel Library Quarterly. 20(2), 46-72.

Maddi, Salvatore R. and Kobasa, Suzanna C. (1984). The hardy executive: health under stress. Homewood, III. Dow-Jones Irwin. Quoted in Wood, Robert (1989). Stress among academic librarians and library directors. Retrieved from: http://www.eric.ed.gov/PDFS/ED330350.pdf Accessed on 24.12.2011

Nawe, Juliet (1995). Work-related stress among the Library and Information work force. Library Review. 44(6). 30-37.

Neville, Sandra H. (1981). Job stress and burnout: occupational hazards for services staff. College and Research libraries. 42. 242-247.

Roose, Tina (1989). Stress at the reference desk. Library Journal. 114. 166-167.

Routray, B. and Satpathy, S.K. (2007). Stress management of Library and Information Science professionals in digital environment. LIS E-prints in Library and Information Science. Retrieved from:www.eprints.rclis.org

Schneider, Margaret S. (1991). Stress and job satisfaction among employees in a public library system with a focus on a public service. Library and Information Science Research. 13(4).385-404.

Speilberger, Charles D. (1966). Theory and Research of Anxiety. Anxiety and behaviour. New York. Academic Press.

Wood, Robert (1989). Stress among Academic Librarians and Library Directors. Retrieved from: http://www.eric.ed.gov/PDFS/ED330350.pdf Accessed on 24.12.2011

Yerkes, Robert M. and Dodson, John D. (1908). The relation of strength of stimuls to rapidity of habit-formation. Journal of Comparative Neurology and Pshychology. 18. 457-482. Wood, Robert (1989). Stress among academic librarians and library directors. Retrieved from: http://www.eric.ed.gov/PDFS/ED330350.pdf. Accessed on 24.12.2011 